\title{
Assessment of Tobacco Control Policy Instruments, Status and Effectiveness in Africa: A Systematic Literature Review
}

\author{
George N Chidimbah \\ Munthali $(\mathbb{D})^{1,2}$ \\ Xue-Lian Wu (D) \\ Muhammad Rizwan' \\ Gama Rivas Daru (D) \\ Yu Shi ${ }^{1}$
}

'School of Economics and Management, Yangtze University, Jingzhou, Hubei, People's Republic of China; ${ }^{2}$ Finance Department, Mzuzu University, Mzuzu, Malawi
Correspondence: Xue-Lian Wu School of Economics and Management, Yangtze University, I Nanhuan Road, Hubei, Jingzhou, People's Republic of China

Email wuxuelian@yangtzeu.edu.cn
Introduction: The tobacco industry has for decades been associated with environmental damage, health-related diseases, human rights violations and corruption issues. The World Health Organisation formulated the Framework Convention on Tobacco Control with the aim of controlling tobacco production and consumption. Most of the countries on the continent of Africa were also the target of the framework given the high importation and use of tobacco products. The main aim of this study was to find out the current status of tobacco control policies and their effectiveness in Africa.

Material and Methods: This study was a systematic literature review that was conducted between the months of August and November 2020 by extracting data from the databases of PubMed, Elsevier Scopus and Web of Science. Only English articles were culled from the retrieved papers. Out of the 910 papers retrieved, only 17 papers from African countries were selected on the quality synthesis after meeting the inclusion criteria.

Results: The results of the study showed that three governance resources were identified of regulatory $(64.70 \%, \mathrm{~N}=11)$ which had smoke-free environment, advertisement bans, and cessation programs, economics $(29.41 \%, \mathrm{~N}=5)$ which were taxation measures and informative $(5.886 \%, \mathrm{~N}=1)$ which were mass media campaigns. Furthermore, Western African countries especially South Africa reported many pronouncements on smoke-free environment and taxation measures. Mass media campaigns proved to be more effective policies as compared to others.

Conclusion: This study recommends that the future research should be done on the effectiveness of mixed policy instruments as compared to single application. Furthermore, the researcher recommends the use of more informative policies in dealing with inelastic behaviours like those related to tobacco due to the addictive nature.

Keywords: tobacco farming, tobacco control policy, tobacco-related diseases, Africa tobacco control, WHO FCTC

\section{Introduction}

The tobacco industry is one of the well-established industries in the world which has for decades been regarded as a source of employment and other social economic benefits to those that are involved and other people at large who happen to support it. ${ }^{1-3}$ However, there is a debate on this, as it is also argued with compelling evidence that through the cultivation and consumption of tobacco, the industry has also brought a lot of direct and indirect adverse impacts on almost all aspects of human life and the environment. For example, it is believed that ecological and environmental challenges have been exacerbated through deforestation, health- 
related problems through the consumption of tobacco end products like smoking cigarettes, social-human rights related challenges for special minority groups of women who are being mistreated on tobacco estates and children who are being deprived of their fundamental right to education by keeping them on tobacco farms other than let them go to school. Children are either forced to provide child labour or merely forced to stay with their parents in these tobacco estates. ${ }^{4-7}$

Literature indicates that at least 8 million people die each and every year due to tobacco- related activities, end products usage of which close to $80 \%$ of these tobacco users are from low- and middle-income countries of Africa and Middle East, where there are high consumption rates of the tobacco-related products. ${ }^{8-11}$ With these pervasive impacts on human life, it led further to the declaration of tobacco as an epidemic by the World Health Organisation (WHO) on 15 March 2015. ${ }^{12,13}$ In addition to that, there is also evidence that man-made practices like continuous cutting down of trees, excessive pesticide usage, monocropping planting pollutions through curing of tobacco and smoking, etc., which are associated with tobacco practices brings about floods, droughts, unfavourable climate, dependence on one cash crop, are said to be some of the main factors that affect food security in recent times all across the globe with developing economies being the most affected ones. ${ }^{14-16}$ Upon looking at all these facts, tobacco industry has for the past decade attracted the attention of global leaders who are compelled to take necessary steps in order to control its production and consumption. As such, tobacco control policies in many economies have always taken centre stage of policy making with regard to the formulation and implementation of sound policy instruments that would see the control of tobacco. This global attention was championed by the WHO in 2003 at its annual meeting in Geneva by formulating Framework Convention on Tobacco Control (FCTC) which acts as an agreement where individual member countries are legally bound to support the implementation and enforcement of the agreed policies on tobacco control. ${ }^{13,17-19}$ WHO FCTC articles defined "tobacco control" as a range of supply, demand and harm reduction strategies that aim to improve the health of a population by eliminating or reducing their consumption of tobacco products and exposure to tobacco smoke. ${ }^{13}$

Africa is not only a continent that has a lot of major tobacco producing countries like Zimbabwe, Malawi, Zambia, Mozambique, South Africa, etc., but also a major market for tobacco products especially cigarettes. ${ }^{20-22}$ Despite the intervention by the WHO to reduce the tobacco epidemic not all the tobacco producing countries are members to the WHO FCTC. For example, some countries in Africa like Malawi, South Sudan and Eritrea have not yet signed or ratified this framework being among major producing and consuming countries of tobacco. ${ }^{23}$ However, literatures indicate that much as some countries are not part of the FCTC still there is some level of tobacco control policies being applied directly or indirectly either by Non-Governmental Organisations (NGOs) or government departments in these said countries. ${ }^{9,24,25}$ In Africa, just like other in other continents, countries that are signatories to the FCTC agreement have formulated tobacco control policies based on the guidelines that are the laid down in the FCTC number 1-23. These are implemented and enforced differently in each country in accordance with the prevailing political will and other social economic factors. ${ }^{13,25,26}$

According to the global progress report on tobacco implementation, the results on the African region in general and countries individually, performance in terms of implementing the FCTC has shown uneven distribution in most regions. ${ }^{27,28}$ For example, in the eastern African region, countries like Mauritius, Madagascar and Seychelles have registered high level of tax implementation (Article 6 - Price and tax measures to reduce the demand for tobacco) as compared to the western region countries like Benin and Guinea-Bissau. ${ }^{28}$ Despite some uneven distribution, to some levels statistics indicate that there has been at least an improvement in all regions in the implementation of smoke-free policies (Article 8 Protection from exposure to tobacco smoke) especially in health care service places and institutions of education as compared to indoor offices, restaurants, pubs and bars, with countries like Namibia, Madagascar, Seychelles, Benin and Burkina Faso registering an impressive implementation rate of close to $100 \%$ of full smoke free in all public places. ${ }^{28}$ In addition to that, in the western region reports indicate that there are high levels of the implementation of bans on direct tobacco advertisements (Article 13 - Tobacco advertising, promotion, and sponsorship (TAPS)) as compared to the central region with countries like Angola and eastern region with countries like Malawi, Zambia and Zimbabwe still lagging behind. On supporting the cessation implementation programs, it is gratifying to note that in all regions of Africa there is pronounced progress in the implementation of smoking cessation 
programs (Article 14 - Demand reduction measures concerning tobacco dependence and cessation) support available as compared to nicotine replacement therapy included in essential medicines list and national toll-free quit line which indicated low levels of implementation. Lastly, countries in the southern region like South Africa, Botswana and Lesotho have recently registered remarkable progress in implementing programs that are aimed at striking against the high level of prevalence of tobacco use among adults as compared to the western region countries on the continent like Nigeria and Ghana. ${ }^{28}$

Studies on tobacco control policies have been conducted for decades in all regions of Africa. There have been a number of reasons that have enormously contributed to the pronounced scholarly interest on the continent of Africa. First of all, Africa is home to major tobacco producing countries. Africa also provides a huge lucrative market base for the tobacco end products. Lastly, Africa ranks among the most adversely affected regions by the tobacco industry. ${ }^{22,25}$ These studies have tackled almost all tobacco control policies. However, the majority of them tended to concentrate on economic policies like taxation ${ }^{29-31}$ and regulatory-like smoke-free environment. ${ }^{32-34}$ The vast majority of literature indicates that the application of such policies and research findings has been facing some difficulties in many setups due to the social economic benefits that are inherently attached to the tobacco industry and the involvement of politicians in the industry who are also in policymakers. ${ }^{25}$ Much as there have been trends which have provided in-depth insights, these studies have put much emphasis on the formulation of tobacco control policies and the implementation of those policies ${ }^{32}$ rather than looking at their effectiveness when applied individually as an instrument or by a combination of different instruments on a broader geographical area.

In this study, we aimed at finding out the current status and effectiveness of tobacco control policy instruments or tools in Africa and also trying to assess a slew of factors that have enormously contributed to their effectiveness by comparing the regional geographical boundaries. By doing so, this paper sought to bridge try to fill the research hiatus that is still apparent in the existing literature. We have focused on the African continent informed by an understanding that most of the countries in Africa are just developing, they largely depend on agricultural activities for their GDP, food security, etc. and that they are not only among the largest producers of tobacco on a global scale, but also consumers who are heavily affected by its adverse negative impacts. ${ }^{18,22,35-37}$

In order to achieve the set aims, this study was guided by the following research questions.

(i) What are the current identifiable policy instruments that have been formulated and implemented in Africa?

(ii) What is known from the research evaluating the impact of tobacco control policies in Africa?

(iii) What are the policy evaluation gaps in Africa and in which regions of Africa are studies most needed?

\section{Materials and Methods \\ Research Variables Dependent Variable}

Effectiveness was put as a dependent variable in this research. An effective instrument was defined as an instrument that was able to meet or achieve the goal for which it was formulated, implemented and enforced..$^{38-40}$ ie an instrument that was able to demonstrate the ability to reduce tobacco consumption and exposure of tobacco smoke with the main focus placed on the key demand management articles as defined by WHO FCTC in articles $(6,8,12,13,14) .{ }^{13}$ Conversely, a policy instrument was regarded as ineffective if it fell short of meeting the aforementioned definition. Measurement on effectiveness was done by using a scale of $0-2$. Any report that portrayed a policy instrument that indicated an ability of an ineffective report was given a $0=($ ineffective) point, any report showing a partial effectiveness was given a $1=$ (partial effective) point, while any report indicating an effectiveness of policy instrument was given a $2=($ effective) point (see Supplementary Data Analysis).

\section{Independent Variables}

Literature indicates that policy instruments can be formulated, implemented and enforced by either the governmental or NGOs based on the one who is overseeing it. ${ }^{40,41}$ This study regarded those policies led by the government and the non-governmental organisations to be part of the independent variables. Furthermore, policy instruments were categorized into three groups. The first group being regulatory in nature if it restricted or allowed behavioural options, the second one economic in nature if it involved the cost-benefits of the options and lastly informative in nature if it involved informing the masses about different 
options. ${ }^{38-40,43}$ There are many characteristics of a policy instrument that could facilitate or scupper its effectiveness when it is being applied. Some of these include i) the aim of the instrument, ii) spatial orientation of an instrument, iii) the actors involved in the instrument, iv) strategy used to promote the instrument, and v) how the instrument is being applied, either singularly or blended with others. ${ }^{44}$

\section{Study Design and Protocol}

This study was conducted systematically by reviewing the literature from peer reviewed social science journal databases. A first literature search was done in the first week of the month of September 2020 and final search was conducted in November 2020 by following the PRISMA (Preferred Reporting Items for Systematic Reviews and Meta-Analyses) guidelines for conducting systematic literature reviews, after posting the preprint on research Square on 17 November with https://www.researchs quare.com/article/rs-109036/v1 all the comments obtained from experts were finally corrected and duly incorporated in the final paper on 30th January $2021^{45,46}$ (see Supplementally Appendix Table A1).

\section{Search Strategy and Data Sources}

On search strategy and data sources, the study relied on data that was searched and retrieved from the database of PubMed, Elsevier Scopus and Web of Science by using a combination of the keywords of "tobacco control policies in Africa", 'tobacco policy control instruments', 'tobacco control policy tools. The researchers in special cases intentionally revisited PubMed database because of the nature of our current study topic which related to health and environment protection in nature and also to ensure that the quality of the papers indexed in this database is high. Two independent researchers (Mr. GNCM and Mr. GRD) checked the reference list of selected studies that were retrieved to ensure that they were not only relevant to the topic, but also that we have included all the up-to-date literature from the eminent scholars. The first criterion was the year of publication which ranged from 1986 to 2020; thereafter, the collection was subject to screening by language so that only papers published in English were culled from the blizzard of papers (see sup plementally Appendix Table A2).

\section{Eligibility Criteria and Article or Study Selection}

For an article to be included in the final qualitative synthesis, it was supposed to meet all of the following six criteria: i) the article should be written in English language, ii) the article should concern the application of tobacco control policy instrument or tool either through government or Non-Governmental perspective, iii) the article should have a geographical area within Africa or composed of developing country in Africa, iv) the article should either be concerned with tobacco production or consumption, v) the article should have focus on the key demand management articles like $(6,8,12,13,14)$, vi) the article should not be a duplicate of another (this was managed through using Mendeley software). Lastly, all articles that could not meet these criteria, conference papers which were not peer-reviewed, and others that just expounded on the formulation of policy instruments were excluded from the final qualitative synthesis.

\section{Risk of Biasness and Quality Assessment}

The risk of biasness and quality assessment for each source included in this study was conducted by two independent researchers (Mr. GNCM and Mr. GRD) using modified Newcastle Ottawa quality assessment scale for included studies applied and used by other researchers in the field, ${ }^{47}$ the included studies were grouped from good studies to unsatisfactory studies based on previous literature grouping on the instrument ${ }^{47-49}$ (See Table 1). Furthermore, to enhance the quality and reduce the biasness of the results, other two impartial researchers (Dr. WX and Ass. Prof. MR) crosschecked the work of the first two researchers and necessary corrections were made to enhance the quality of the paper after some discussions.

\section{Data Extraction and Coding}

On data extraction, this article modified the frameworks of assessing policy instruments' effectiveness applied in other areas of studies by adding other elements found in effective policy assessment handbooks. ${ }^{18,41,44}$ As such, there was a predesigned Excel sheet form which was used to extract the data from the selected literature. Based on the framework of assessing the effectiveness of instruments, the characteristics of the data extracted were the following: author's details, year of the study, country/ 


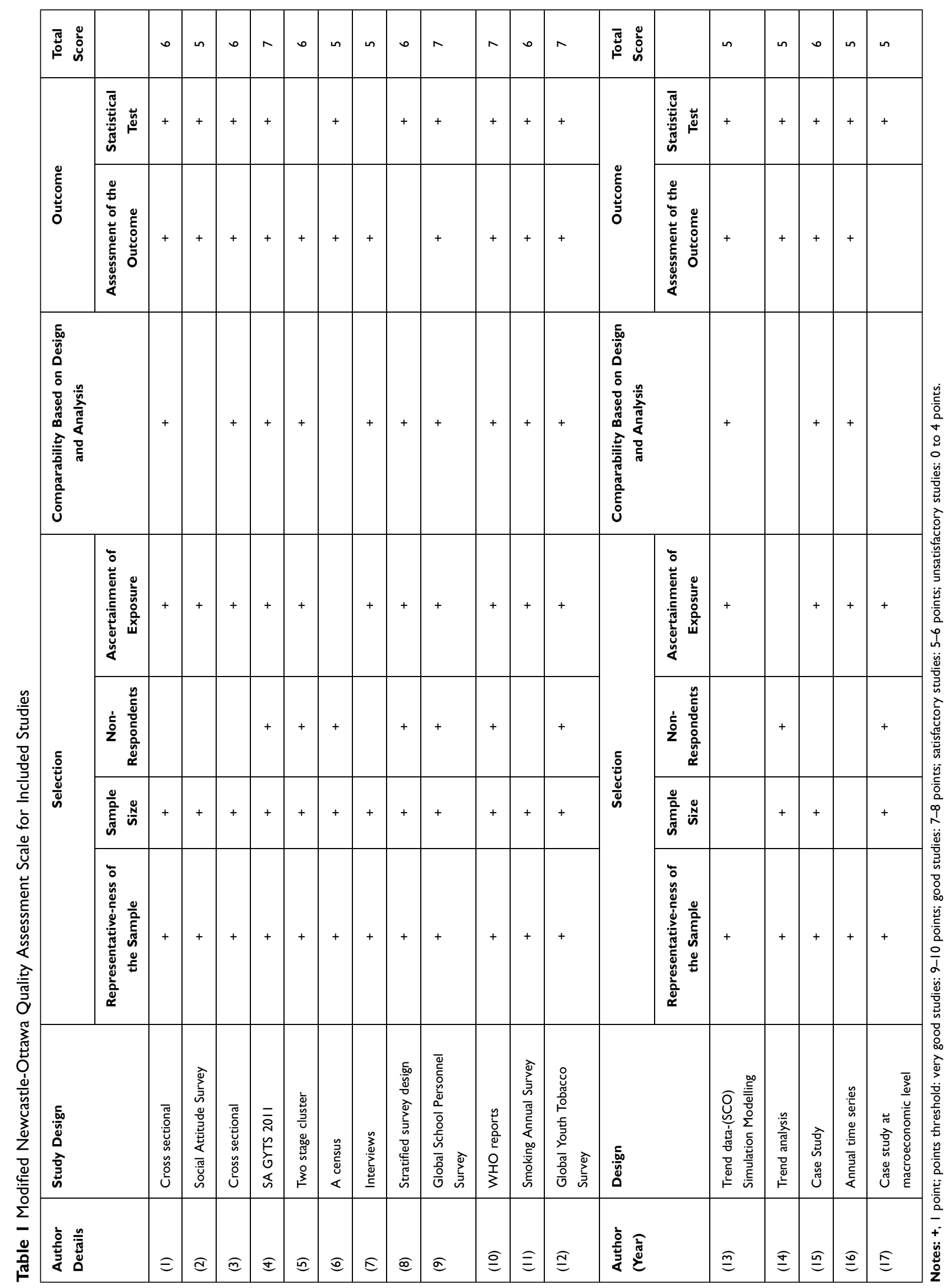


geographical application, aim of the study, the target of the policy instrument, the enforcer of the policy instrument and the results of the instrument. Any country reporting on the policy instrument was given a single point on the type, nature, region and effectiveness of the instrument reported.

\section{Data Analysis}

After the extraction of the data from the retrieved literature, data was captured and entered into the Excel sheet where all the descriptive data was analysed to produce frequency tables and graphs where necessary in order to present the findings of the study. All discrepancies found at this stage were also rectified by a third researcher (Miss. SY).

\section{Results}

\section{Number of Studies}

Firstly, about 910 studies were fished out from the databases after an initial search of the literature. A total number of 775 records were screened after the removal of the duplicates using Mendeley software, of which 646 were excluded for not meeting the inclusion criteria upon looking at the abstract during the initial review. Furthermore, a total number of 129 were checked for eligibility from which 112 records were excluded with reasons, making only 17 studies fit for inclusion into the final quality synthesis after meeting all the inclusion criteria (see Figure 1).
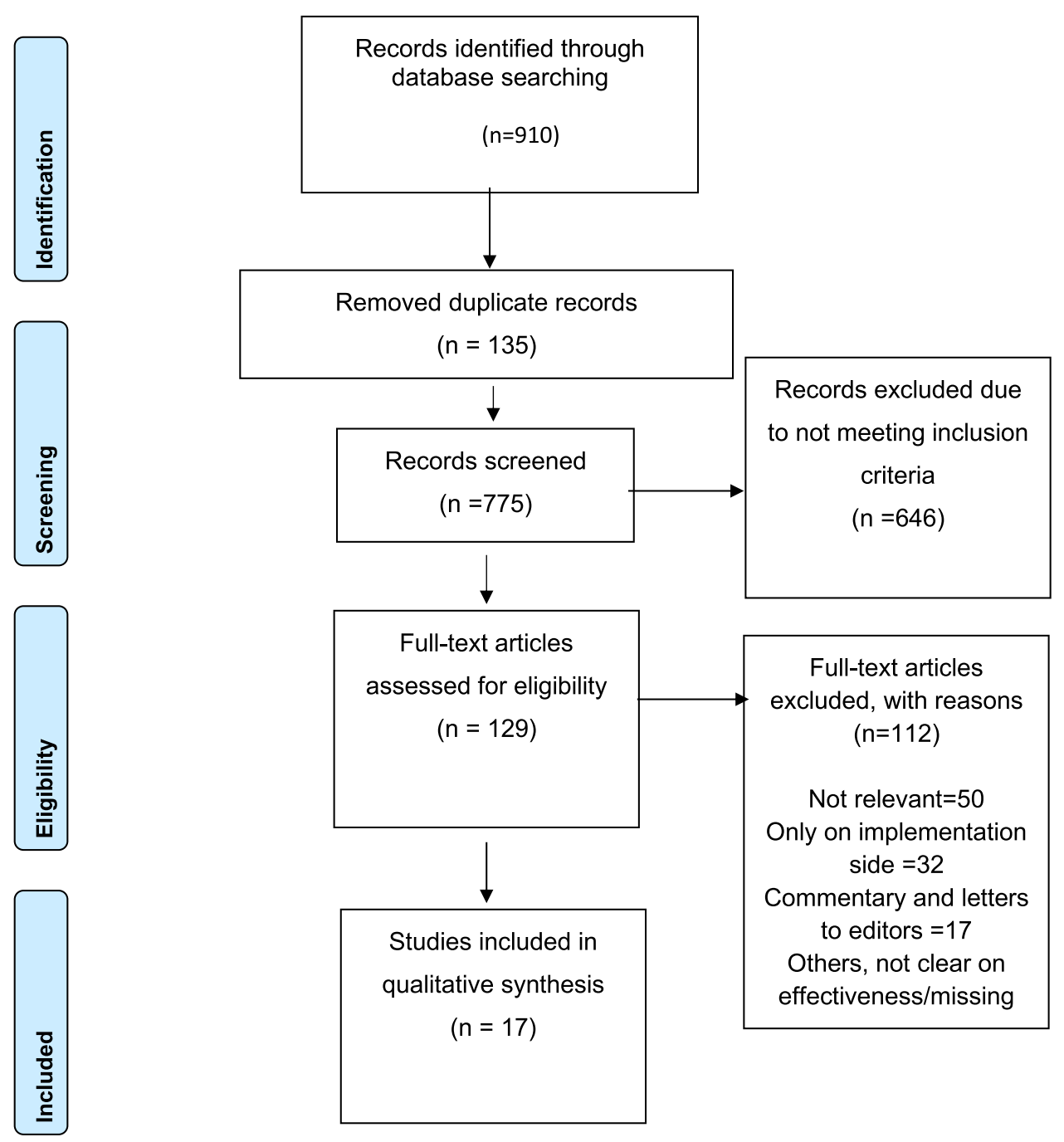

Figure I Shows PRISMA Flow diagram of methodological framework adapted from Page MJ, McKenzie JE, Bossuyt PM, Boutron I, Hoffmann TC, Mulrow CD, et al. The PRISMA 2020 statement: an updated guideline for reporting systematic reviews. BMJ 2021;372:n7I. Creative Common. ${ }^{42}$ 


\section{Study Characteristics}

\section{Governance Resources and Study Overview}

On governance resource type, after the analysis of the results, it was shown that out of the 17 studies included in the quality synthesis about $64.70 \%(\mathrm{~N}=11)$ policies reported were based on regulation, ${ }^{10,32,33,50-55} 29.41 \%$ $(\mathrm{N}=5)$ dwelt on the economic nature ${ }^{29,30,56-59}$ and lastly 1 report was based on Informative side and constituted $5.88 \%(\mathrm{~N}=1)$ percentage $^{56}$ (see Table 2 and Figure 2). The results in Table 3 show a general overview of the main characteristics of the 17 studies that were included in the quality synthesis.

\section{Reported Policy Instruments}

On specific reported instruments the results revealed that the following were the instruments that were reported that far: i) Smoke-free environment policies, ii) Cessation program policies, iii) Advertising bans policies, iv) Taxation policies, v) Mass media campaign policies (see Figure 2).

\section{Regional Distributions of Reports}

On regional distribution, out of the 5 instruments identified in 17 studies it was found that about $5.88 \%(\mathrm{~N}=1)$ were from Egypt in the northern part of Africa, 47.05\% (N=8) were reported from South Africa and Botswana from the Southern Africa, about 23.52\% ( $\mathrm{N}=4)$ were reported from Gambia, Nigeria and a survey of (Benin, Burkina Faso, Cape Verde, Côte d'Ivoire, Gambia, Ghana, Guinea, Mali, Mauritania, Niger, Nigeria, Senegal and Sierra Leone) from the western part of Africa, about 17.64\% (N=3) were reported from Uganda and Mauritius which are from the eastern side of Africa and lastly about 5.88\% $(\mathrm{N}=1)$ were from a survey that comprised 29 African countries (see Figure 3).

\section{Country Distribution of Studies}

On country distribution, out of the 17 reports identified, the results showed that Egypt reported only about 5.88\% $(\mathrm{N}=1)$ policy instrument of smoke free, South Africa reported $44.12 \% \mathrm{~N}=7.5$ of all four policies (with 0.5 having done in Botswana and South Africa in one report), Botswana reported 2.94\% ( $\mathrm{N}=0.5)$ (shared with $\mathrm{SA}$ on a singular report) of advertising bans, Gambia reported $5.88 \%(\mathrm{~N}=1)$ of tax control policies, Nigeria reported $5.88 \%(\mathrm{~N}=1)$ of smoke-free environment, Ghana reported $5.88 \%(\mathrm{~N}=1)$ of smoke-free and cessation programs, a survey of countries (Benin, Burkina Faso, Cape Verde, Côte d'Ivoire, Gambia, Ghana, Guinea, Mali, Mauritania, Niger, Nigeria, Senegal and Sierra Leone) from the western part of Africa reported 5.88\% $(\mathrm{N}=1)$ of cessation program, Uganda reported $11.76 \%(\mathrm{~N}=2)$ of smoke-free environment control policies, Mauritius reported 5.88\% $(\mathrm{N}=1)$ of tax control policies and lastly about $5.88 \%$ $(\mathrm{N}=1)$ were from a survey that comprised of 29 African countries (Southern Africa: Namibia, Swaziland, South Africa and Lesotho. West Africa: Burkina Faso, Ghana, Mauritania, Niger, Senegal, Togo, Guinea Bissau and Sierra Leone. Central Africa: Democratic Republic of the Congo (Kinshasa), Republic of the Congo, Central African Republic (Bangui) and Cameroon (Central District). Eastern Africa: Djibouti, Somalia (Somaliland), Malawi, Uganda, Eritrea, Seychelles, Mauritius, Rwanda and Zimbabwe (Harare), Northern Africa: Morocco, Tunisia, Libya and Sudan) of cessation program control policies (see Figure 4).

\section{Tobacco Instruments' Effectiveness} Effectiveness When Using a Single Policy Instrument While assessing the effectiveness of reported policy instruments when used as stand-alone instruments the results indicated that smoke-free environment policies were $13 \%$

Table 2 Showing Total Number of Reports Reported (N=I7)

\begin{tabular}{|l|l|c|c|c|}
\hline Governance Resource & Instruments & FCTC Articles & Frequency & Percentage \% \\
\hline \multirow{3}{*}{ Regulatory } & Smoke-free Environment/policies & 8 & 8 & 47.05 \\
\cline { 2 - 5 } & Cessations Programs & 14 & 2 & 11.76 \\
\cline { 2 - 5 } & Advertising bans & 13 & 1 & 5.88 \\
\hline Economic & Taxes & 6 & 5 & 29.41 \\
\hline Informative & Mass Media Campaign & 12 & 1 & 5.88 \\
\hline
\end{tabular}




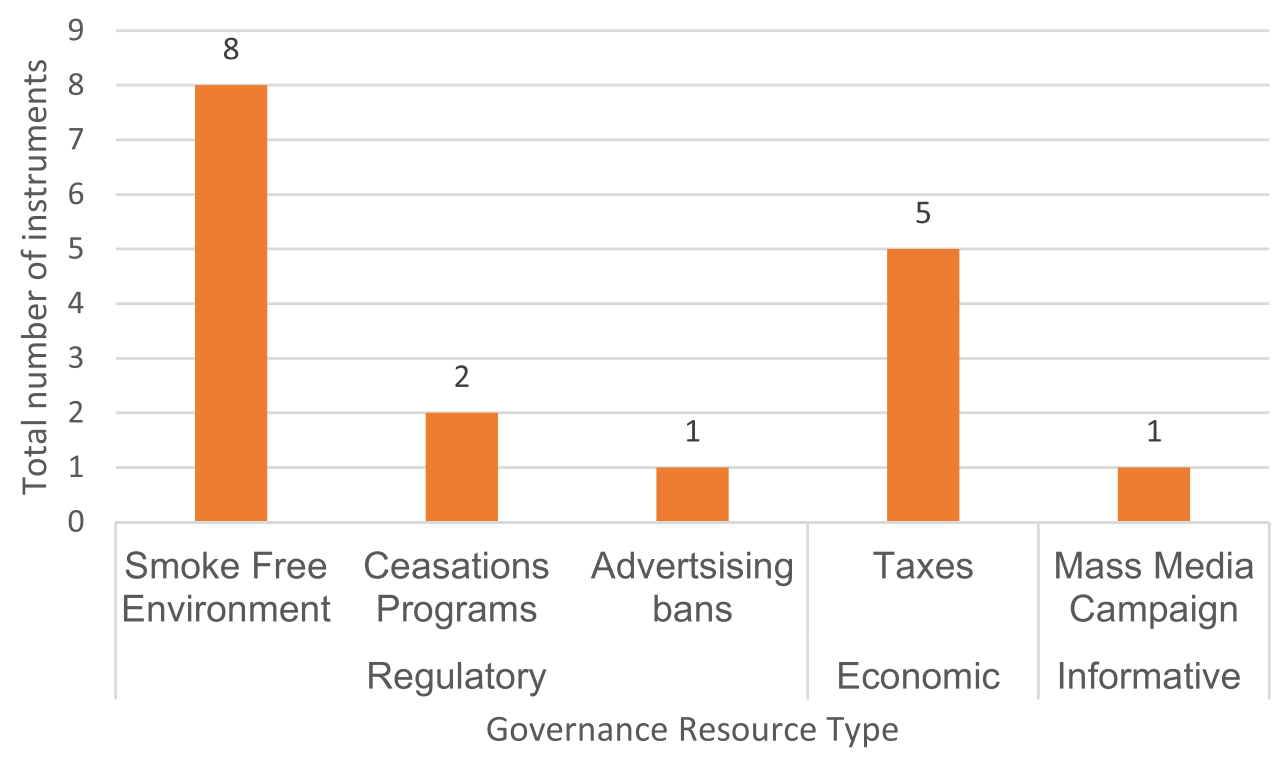

Figure 2 Types of governance resources and instruments reported.

effective, about $63 \%$ were partially effective and $25 \%$ were ineffective, on cessation programs, it is indicated that about $50 \%$ were effective, while the remaining $50 \%$ were partially effective and on taxation policies it indicated that about $60 \%$ were effective, $20 \%$ were partially effective and $20 \%$ were ineffective. Furthermore, on mass media campaign, it demonstrated that the policies were $100 \%$ effective and lastly on advertising bans, the results revealed that all reports were $100 \%$ effective (see Table 4 and Figure 5).

\section{Effectiveness When Used Mixed}

While assessing the effectiveness of the policy instruments when they were applied in a mixed way or blended with the others, in order to achieve a common goal within a particular time, the results showed that free smoke environment reported $100 \%$ effectiveness, cessation program reported $50 \%$ effectiveness and $50 \%$ partial effectiveness, taxation reported $100 \%$ effectiveness, mass media campaigns reported $100 \%$ effectiveness and lastly advertising bans reported $100 \%$ effectiveness (see Table 5 and Figure 6).

\section{Discussion}

The primary objective of this research was to find out the current status of tobacco control policies reported and their effectiveness in Africa. By September 2020 in Africa there were only 3 countries that had not ratified and signed the WHO FCTC policies. However, in one way or another literature indicates that in each and every country including those that are not signatories to the framework, there are at least a certain elements of tobacco control regulation applied either by governments or NGOs directly or indirectly due to the external forces like decline in tobacco demand coming from the countries that have already signed and ratified the WHO FCTC agreement and proved to have taken a step in the implementation of them. ${ }^{23}$

Our review found out that the main leading actors of the policy instruments formulation, implementations and enforcement are government bodies and NGOs associated with health, human rights, the environment, etc., ie, those that take interest in tobacco control policies and their impacts. This is reasonable and in agreement with the procedures laid down by WHO FCTC for the registration of partners in fighting tobacco epidemic. ${ }^{11,23}$ By looking at the nature of the policies, this review further found out that the policies identified are usually planned on timeframe of long-term basis that mostly are applied at a national geographical level targeting those that are either participating or not in the production of tobacco, its consumption, ie, These policies are applied with the main aim of protecting the environment, health and social economic status of the people. On governance resources, it was found that the majority of the policy instruments were regulatory in nature, ie, those that included implementation of smoke-free environment and cessation programs, which were measures taken by the government with the application of rules to guide the tobacco production and consumption. This was not a surprise, as the tobacco control involved the 


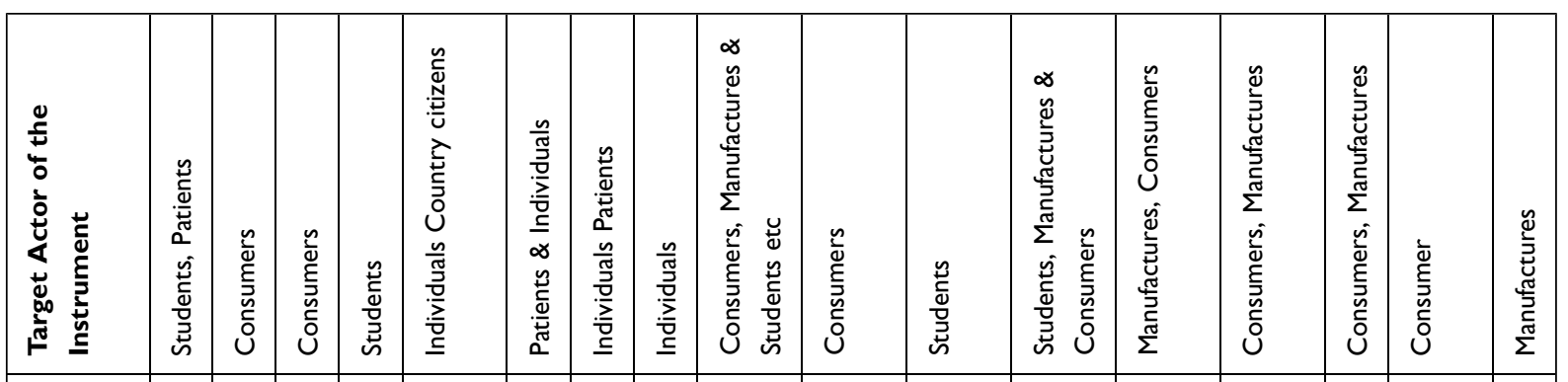

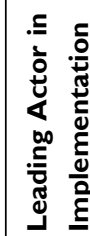

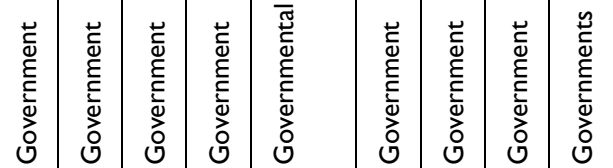

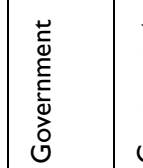

!

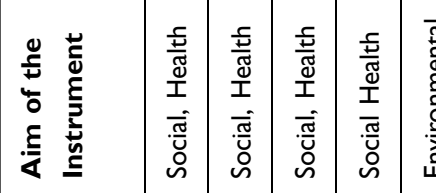

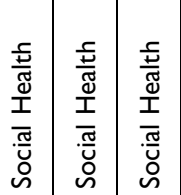

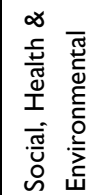

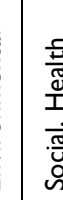

意新

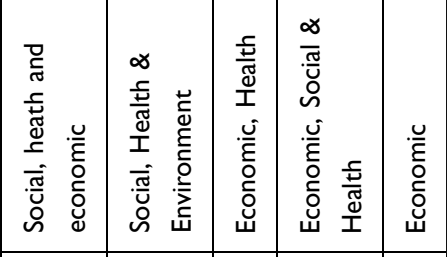

产

锭

高

高

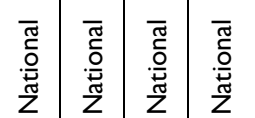

高

高

衰

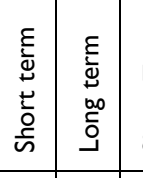

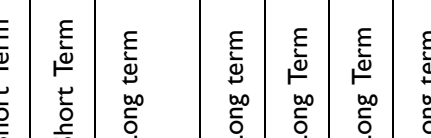

ह

ह

高

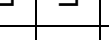

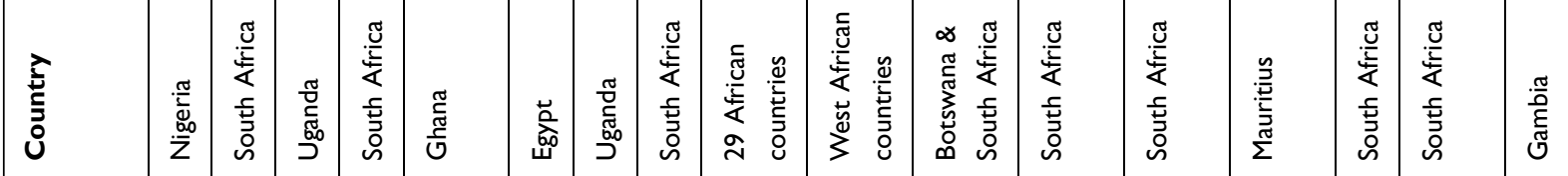

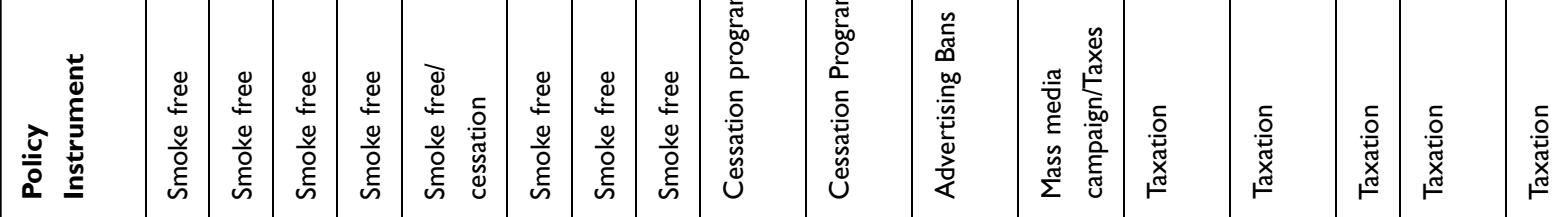

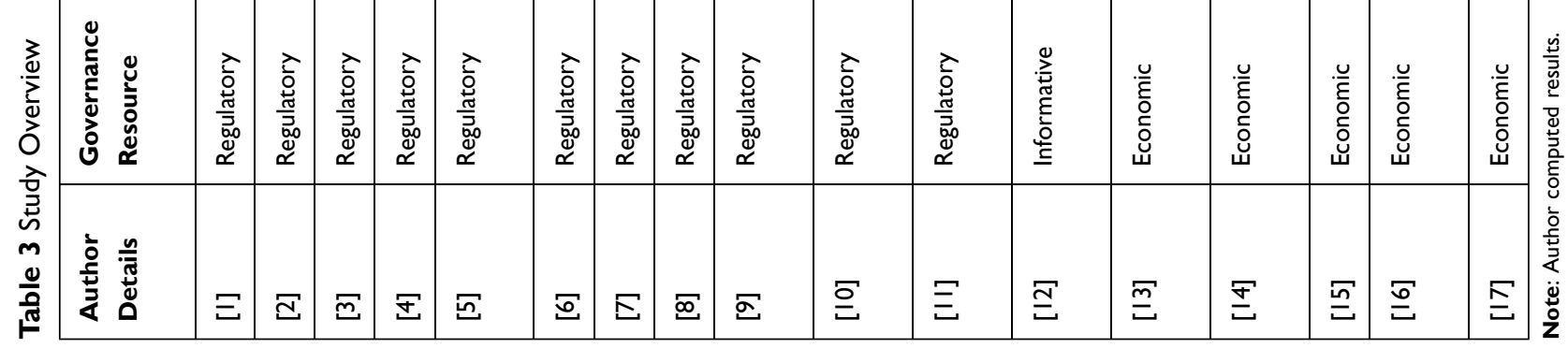




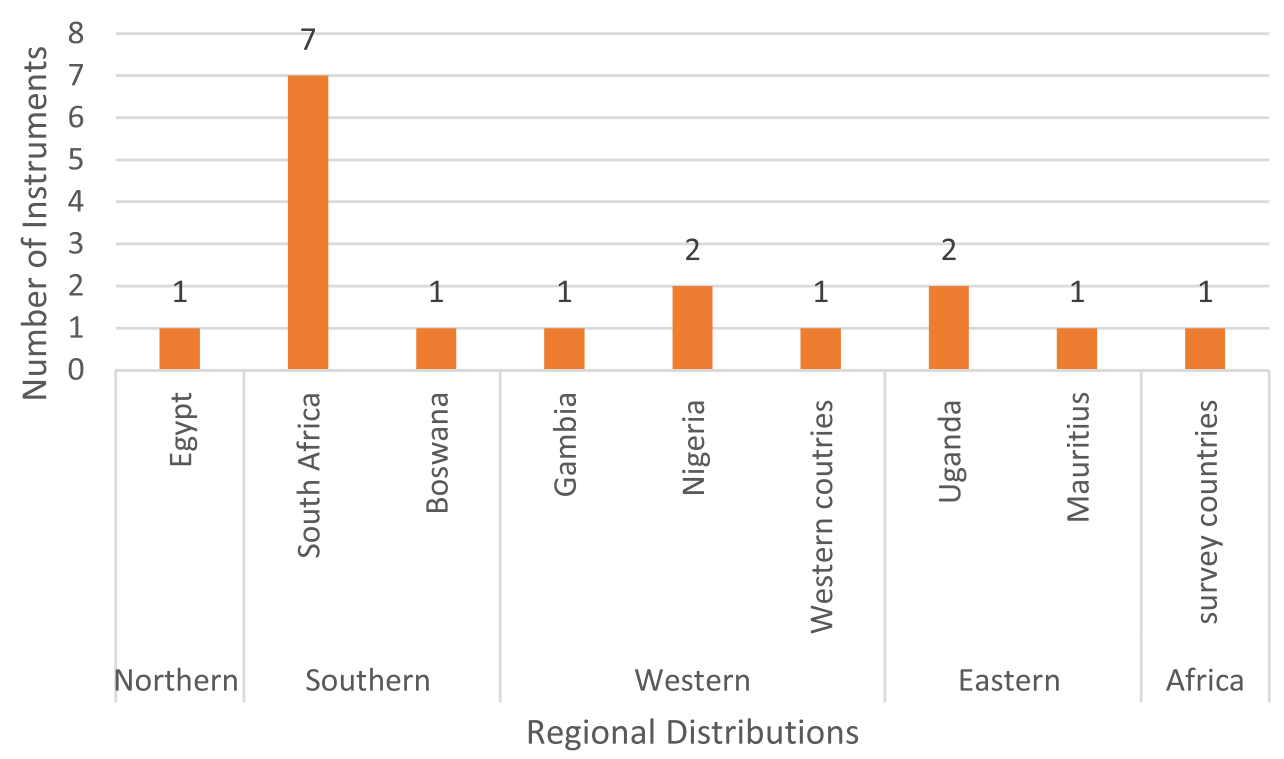

Figure 3 Regional comparisons.

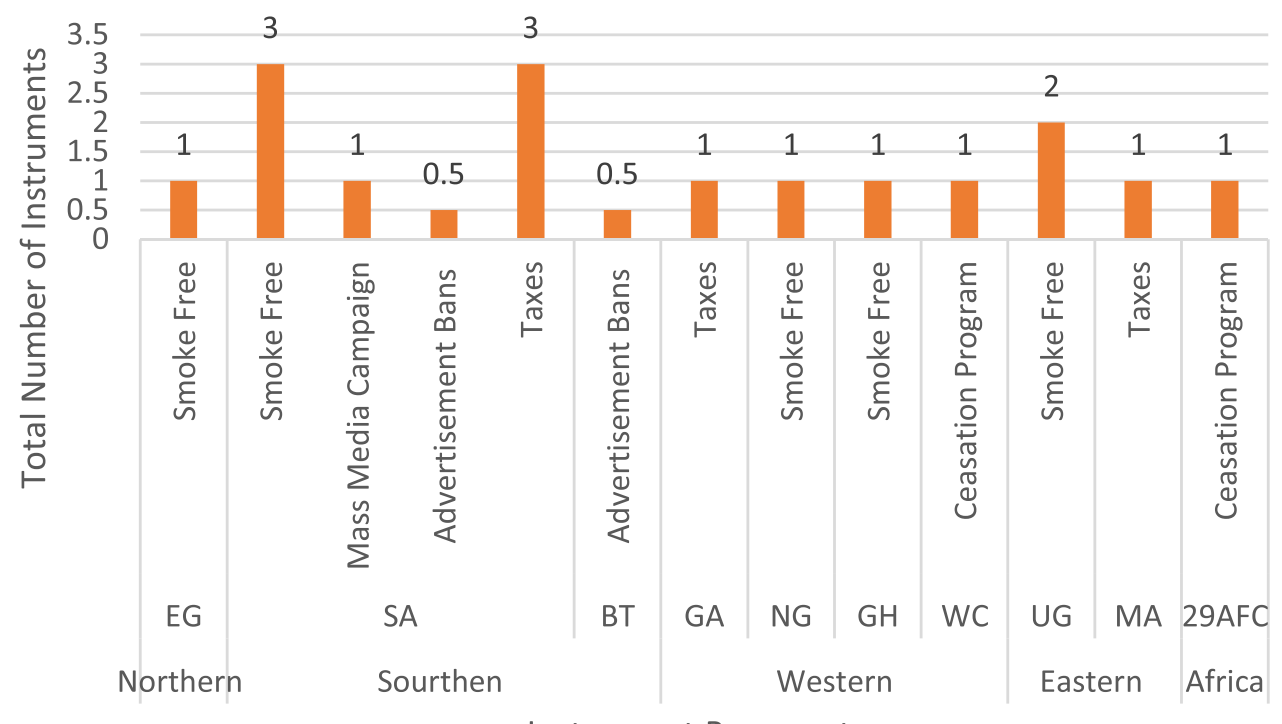

Figure 4 Instruments per country.

Abbreviations: EG, Egypt; SA, South Africa; BT, Botswana; GA, Gambia; NG, Nigeria; GH, Ghana; WC, Western Countries; UG, Uganda; MA, Mauritius; AFR, African Country Survey. ${ }^{60}$

top-level management decisions within the government, which are members of the WHO FCTC that are legally obliged to report on their implementation of and adherence to the policies at each WHO FCTC meeting as decided from time to time. Furthermore, this study has found that there is also much emphasis on promotion of the smoke-free environment because there have been increasing reports about the increasing numbers of mortality rate due to second-hand smoking in the world. As such, these concerns have put much pressure on policymakers to increase awareness and implementation of policies that help not only to reduce second-hand smoke effects but also the total cessation of tobacco consumption. ${ }^{11,13,61}$ On the other hand, the findings of this study also revealed that some countries use economic governance resources of taxation and informative means such as mass media and advertising bans. However, with few studies being reported on taxation measures, it was highlighted that these measures are being applied indirectly to reduce the consumption of tobacco products where the national governments are increasing taxation on the 
Table 4 Instrument Outcome When Applied Singularly

\begin{tabular}{|c|c|c|c|c|c|c|c|}
\hline \multirow[t]{2}{*}{ Instrument } & \multicolumn{4}{|c|}{ Frequencies } & \multicolumn{3}{|c|}{ Percentage } \\
\hline & $\begin{array}{l}\text { Total } \\
\text { Reports }\end{array}$ & Effective & $\begin{array}{l}\text { Partially } \\
\text { Effective }\end{array}$ & Ineffective & Effective & $\begin{array}{l}\text { Partially } \\
\text { Effective }\end{array}$ & Ineffective \\
\hline $\begin{array}{l}\text { Smoke Free } \\
\text { Environment }\end{array}$ & 8 & I & 5 & 2 & $13 \%$ & $63 \%$ & $25 \%$ \\
\hline Cessations Programs & 2 & I & I & 0 & $50 \%$ & $50 \%$ & $0 \%$ \\
\hline Taxes & 5 & 3 & I & I & $60 \%$ & $20 \%$ & $20 \%$ \\
\hline Mass Media Campaign & 1 & I & 0 & 0 & $100 \%$ & $0 \%$ & $0 \%$ \\
\hline Advertising bans & I & I & 0 & 0 & $100 \%$ & $0 \%$ & $0 \%$ \\
\hline
\end{tabular}

Note: Author computed results.

manufacturers of tobacco-related products which at the end reduces the volumes of tobacco end products being produced and consumed like cigarettes. However, this has not proved to be an effective way in many ways because of the inelasticity of tobacco products due to addiction habits by users and, consequently, tobacco manufacturing companies are evading these taxes by shifting the burden on the consumers. ${ }^{62-64}$

On regional comparisons, this review found out that Southern African region countries like South Africa and Botswana filed the majority of policy reports especially in South Africa with tax measures and free smoke environment being the ones on the lead. These results are corroborated by many results that identified high problems of smoking-related diseases in South Africa, which could have attracted the attention of the many scholars. ${ }^{10,52,65}$ However, it can also be argued that since Botswana and South Africa share the border, they could as well share cultural values, trade and other relationships to some extent. This could foster behavioural transfer from one country to another like that of smoking leading to register this high number of reports as being one of the areas that is also negatively affected by the tobacco pandemic. Furthermore, the review found that there were not many

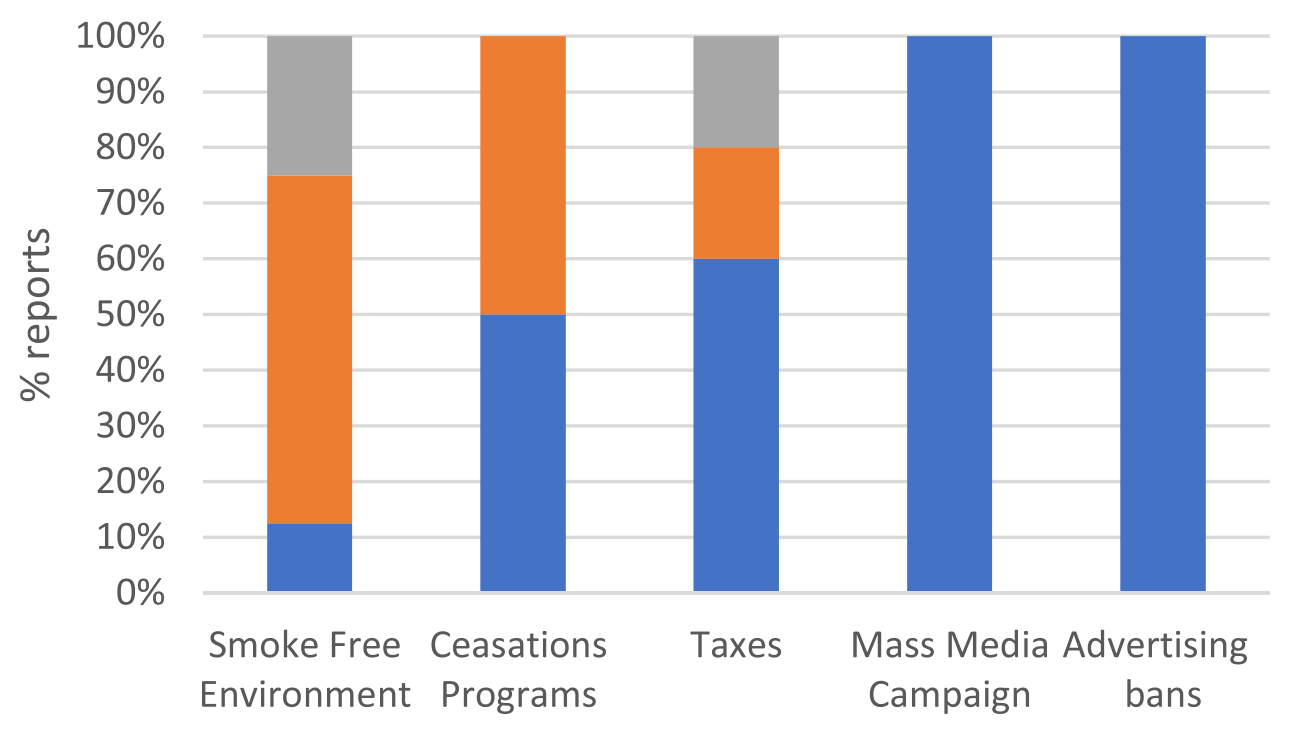

Effective Partially Effective Ineffective

Figure 5 Reported effectiveness when used single. 
Table 5 Instrument Outcomes When Mixed

\begin{tabular}{|c|c|c|c|c|c|c|c|}
\hline \multirow[t]{2}{*}{ Instrument } & \multicolumn{4}{|l|}{ Frequencies } & \multicolumn{3}{|c|}{ Percentage } \\
\hline & Total Reports & Effective & $\begin{array}{l}\text { Partially } \\
\text { Effective }\end{array}$ & Ineffective & Effective & $\begin{array}{l}\text { Partially } \\
\text { Effective }\end{array}$ & Ineffective \\
\hline $\begin{array}{l}\text { Smoke-free } \\
\text { Environment }\end{array}$ & 1 & I & 0 & 0 & $100 \%$ & $0 \%$ & $0 \%$ \\
\hline Cessations Programs & 2 & I & I & 0 & $50 \%$ & $50 \%$ & $0 \%$ \\
\hline Taxes & 1 & I & 0 & 0 & $100 \%$ & $0 \%$ & $0 \%$ \\
\hline Mass Media Campaign & 1 & I & 0 & 0 & $100 \%$ & $0 \%$ & $0 \%$ \\
\hline Advertising bans & I & I & 0 & 0 & $100 \%$ & $0 \%$ & $0 \%$ \\
\hline
\end{tabular}

Note: Author computed results.

reports in Northern and Eastern African countries with only one (1) in Egypt and two (2) in Uganda and Mauritius, respectively. This could be imputed to the palpable lack of scholars' attention in the region due to many reasons such as low tobacco production and political instability. ${ }^{66}$ On the part of the Western African region, Ghana made one report (1), whereas Nigeria registered many policy reports as compared to any other countries with many also on smokefree environments. Nigeria being one of the fastest growing economies in the region, which has also experienced a rapid population growth, has attracted many scholars to research on issues of health and economy within and outside Africa. Furthermore, our study agrees with other studies that found out that South Africa and Nigeria are the leading countries in having many scholarly literature on tobacco control from 1968 to $2017 .^{65}$

In terms of policy effectiveness, this review found out that mass media campaigns and advertising bans were the most effective policies when applied both singularly and mixed. The effectiveness of mass media campaigns and advertising of bans could be attributed to the fact that they are informative in nature, which mainly aims at civic educating people on the dangers of the tobacco-related products. These results of the review are in agreement with economic policy's instruments in reducing consumption of inelastic related products like tobacco, alcohol and drugs etc., where it is proved that civic education helps to reduce the impacts of inelastic products (those associated with addictions). ${ }^{57,63,67}$ Furthermore, cessation programs have indicated that they had equal level of effectiveness and partially effectiveness when applied on singular or mixed. Lastly, taxation policies and smoke-free environment policies had some nature of ineffectiveness due to the reasons that they are economic and regulative in nature that are easily manipulated by the external factors like political will. For example, in terms of taxation many

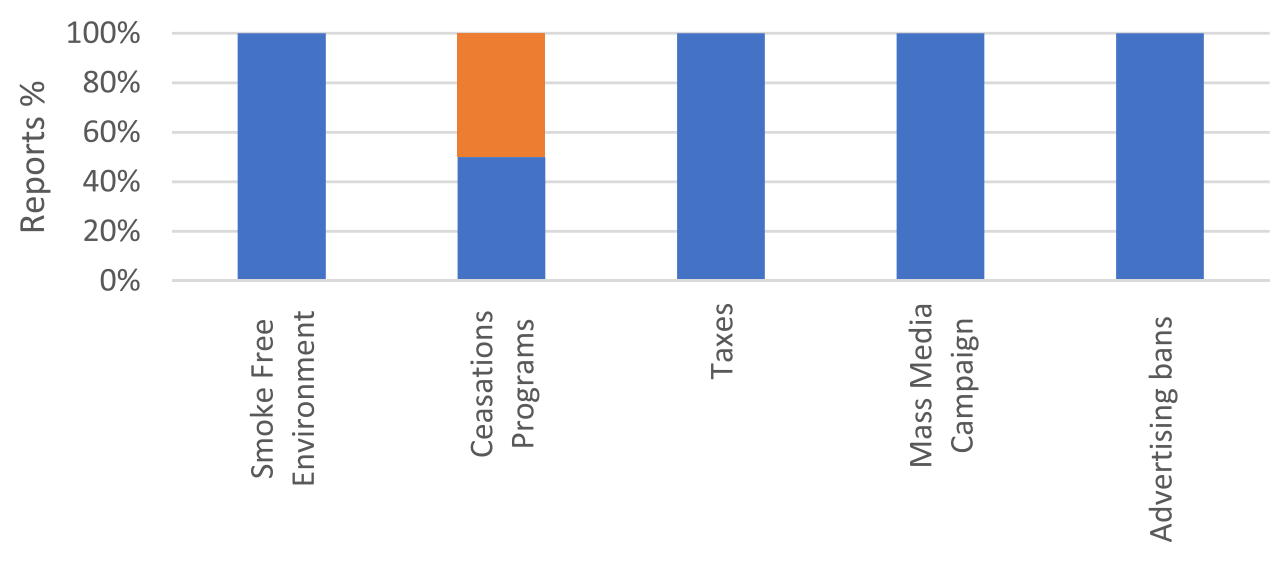

Effective Partially Effective Ineffective

Figure 6 Reported of effectiveness when mixed. 
manufacturing companies tend to shield or override the tax measures by shifting the tax burden of the tobacco to the final consumers who are the end users of tobacco-related products like cigarettes. These are left with no options but to buy the products even though the prices are raised as many of them have serious having addiction problems or habits which are associated tobacco. As a result, the main aim of the governments in implementing the taxation measures and smoke-free environment is being undermined as only a small margin is able to reduce the consumption of tobacco. It is clear in this study that the mixing of the policy instruments helps to achieve greater effectiveness as it has shown that the vast majority of the policies were able to achieve the intended aims, while mixed with others and not as stand-alone policies. These results concur with many results that propagated the mixed approach in policy instruments when the focus was to achieve effectiveness. ${ }^{41,43,44}$

\section{Limitations}

This study also encountered some limitations just like any other systematic review. Firstly, this review only captured articles written and published in English, but in Africa there are some countries that are French and Portuguese speaking which means that some of their studies that could have added value to this research were excluded. However, the number of studies in other languages could be insignificant as many scholars worldwide have started to abstract and to write in English. Secondly, this study relied mainly on four databases of PubMed, Scopus and web of science when collecting the data and this confinement could have excluded some of the studies not indexed in these databases, hence giving a limited focus on the number of studies included in the review, which have further led to some track records of cited lens relying on OECD-based academic sources. The researchers believe this has been raised due to the nature of the topic and its geographical position at hand, which could not lead to misrepresentation of the research findings. Lastly, because this study only aimed at peer-reviewed social science nature articles which are assumed to be of high quality, we did not include the search of grey materials that could have also been a great resource for this review.

\section{Conclusion}

In conclusion, it is a clear fact that in Africa almost all countries are involved in activities that could lead to the reduction of tobacco production and consumption due to the palpably negative consequences that are associated with the tobacco industry. These are healthy, environmental and social-economic in nature. However, this review has highlighted that there is still a need for more work to be done in Africa when it comes to the effectiveness of the tobacco control policies as not many studies are carried out in this area. For instance, it has been discovered that most of the studies that are currently being conducted lay a lot more stress implementation programs than the efficacy of the programs in question.

We recommend the future research to be done on the assessment of an effectiveness of the blend of different policy instruments as compared to the application of single instruments. Furthermore, we give recommendations to policymakers to invest a lot more efforts in those measures that are informative in nature and foster civic education to the people as they proved to be more effective than the other policies due to the inelasticity of tobacco users.

\section{Data Sharing Statement}

All data is provided by the authors; George N Chidimbah Munthali and Dr. Xue-Lian Wu.

\section{Consent for Publication}

All authors give consent for the publication of this paper.

\section{Acknowledgments}

We would like to thank Yangtze University School of Management and Economics and Yangtze University International Student Office for the direction and social support they provided throughout the production process of this paper. Fulsome thanks should also go to Mr. Stones Banda and Mr. John Mshani for the invaluable comments on the first draft of the work. On last note the reviewers and journal comments that we believe have also added value to our paper.

\section{Author Contributions}

All authors made substantial contributions to conception and design, acquisition of data, or analysis and interpretation of data, took part in drafting the article or revising it critically for important intellectual content; agreed to submit to the current journal, gave final approval of the version to be published and agreed to be accountable for all aspects of the work.

\section{Funding}

No funding was provided for this project. 


\section{Disclosure}

The authors declare that there are no competing interests.

\section{References}

1. Munthali GNC, Xuelian W. The future of tobacco industry amidst of COVID-19 -a case of Malawi producing country. Biomed J Sci Tech Res. 2020;27(5):21104-21109. doi:10.26717/BJSTR.2020.27.004566

2. Stoklosa M, Goma F, Nargis N, et al. Price, tax and tobacco product substitution in Zambia: findings from the ITC Zambia surveys. To $b$ Control. 2019;28(Suppl 1):s45-s52. doi:10.1136/tobaccocontrol2017-054037

3. Drope J, Makoka D, Lencucha R, Appau A. Farm-level economics of tobacco production in Malawi. 2016.

4. Hu TW, Lee AH. Women in tobacco farming: health, equality, and empowerment A study conducted in China, Tanzania and Kenya. Public Health Institute. 2016;1-50.

5. Doe J, DeSanto C, Granger D et al. Smoking's immediate effects on the body. Tobacco-Free Kids; 2009. Available from: https://www.tobaccofree kids.org/research/factsheets/pdf/0264.pdf. Accessed June 26, 2021.

6. Kulkarni N. Women and tobacco- an overview. Curr Trends Biomed Eng Biosci. 2017;2(5). doi:10.19080/ctbeb.2017.02.555599

7. Southeast Asia Tobacco Control Association. Child labour in tobacco cultivation in the ASEAN region. 2013. Available from: https://www.google.com.hk/ url sa $=t \& r c t=j \& q=\&$ esrc $=$ s\&source $=$ web\&cd $=\& c a d=$ rja\&uact $=8 \& v e d=$ 2ahUKEwjewfb9wr3xAhVQHzQIHaT8DisQFjAAegQIAxAD\&url=https $\% 3 \mathrm{~A} \% 2 \mathrm{~F} \% 2 \mathrm{Fseatca}$. org\%2Fdmdocuments\%2FChildLabor\%2520Final $\%$ 25202013.pdf\&usg=AOvVaw2fFmzy4OzfW35SKV1J0tUJ.

8. Vardavas C, Nikitara K. COVID-19 and smoking: a systematic review of the evidence. Tob Induc Dis. 2020;18(March):1-4. doi:10.18332/tid/119324

9. Bennett DA, Krishnamurthi RV, Barker-Collo S, et al. The global burden of ischemic stroke: findings of the GBD 2010 study. Glob Heart. 2014;9(1):107-112. doi:10.1016/j.gheart.2014.01.001

10. Ayo-Yusuf OA, Olufajo O, Agaku IT. Exposure to secondhand smoke and voluntary adoption of smoke-free home and car rules among non-smoking South African adults. BMC Public Health. 2014;14 (1):580. doi:10.1186/1471-2458-14-580

11. WHO-FCTC. Tobacco. World Health Organization; 2020. Available from: https://www.who.int/news-room/fact-sheets/detail/tobacco. Accessed September 24, 2020.

12. de la Salud AM. WHO framework convention on tobacco control. Rev Esp Salud Publica. 2003;77(4):475-496. doi:10.1590/S113557272003000400005

13. World Health Organisation. Who framework convention. WHO Framew Conv Tob Control; 2003. Available from: http://www.who.int/ tobacco/framework/WHO_FCTC_english.pdf. Accessed June 26, 2021.

14. World Economic Forum. Food security and why it matters | World Economic Forum. WEF; 2020. Available from: https://www. weforum.org/agenda/2016/01/food-security-and-why-it-matters/. Accessed September 20, 2020.

15. Schleifer P, Sun Y. Reviewing the impact of sustainability certification on food security in developing countries. Glob Food Sec. 2020;24:100337. doi:10.1016/j.gfs.2019.100337

16. Mayer M, Gueorguieva R, Ma X, White MA. Tobacco use increases risk of food insecurity: an analysis of continuous NHANES data from 1999 to 2014. Prev Med. 2019;126:105765. doi:10.1016/j. ypmed.2019.105765

17. Adebiyi A, Oluwafemi A. Assessment of tobacco control efforts in three Sub-Saharan African countries. Niger Postgrad Med J. 2017;24 (1):8. doi:10.4103/npmj.npmj_177_16

18. Sanni S, Hongoro C, Ndinda C, Wisdom JP. Assessment of the multi-sectoral approach to tobacco control policies in South Africa and Togo. BMC Public Health. 2018;18(S1):962. doi:10.1186/ s12889-018-5829-3
19. World Health Organization. WHO Global Report on Trends in Prevalence of Tobacco Use. 3rd ed. 2000.

20. Davies P. Malawi: addicted to the leaf. Tob Control. 2003;12 (1):91-93. doi:10.1136/tc.12.1.91

21. Ali AYM, Safwat T, Onyemelukwe G, et al. Smoking prevention and cessation in the Africa and middle east region: a consensus draft guideline for healthcare providers - executive summary. Respiration. 2012;83(5):423-432. doi:10.1159/000337726

22. Blecher E, Ross H. Tobacco use in Africa: tobacco control through prevention. Am Cancer Soc. 2013.

23. Framework Convention Alliance. Parties to the WHO FCTC (ratifications and accessions) - Framework Convention Alliance. FCA; 2020. Available from: https://www.fctc.org/parties-ratifications-andaccessions-latest/. Accessed September 24, 2020.

24. Brenya E. Trans-border advocacy network in tobacco control: the adoption of WHO-FCTC best practices into domestic laws in Ghana and Malawi. ProQuest Diss Theses; 2012. Available from: http:// search.proquest.com/docview/1112049333? accountid $=10673 \%$ 5Cnhttp://openurl.ac.uk/athens:_edu?url_ver=Z39.88-2004\&rft_val_ $\mathrm{fm}=$ info:ofi/fmt:kev:mtx:dissertation\&genre=dissertations $+\% 26+$ the ses\&sid=ProQ:ProQuest + Dissertations $+\% 26+$ Theses + Global\&atitle $=$ \&ti. Accessed June 26, 2021.

25. Drope J. Tobacco control in Africa: people, politics and policies. 2011. doi:10.7135/UPO9780857288134.

26. Reddy P, James S, Sewpaul R, et al. A decade of tobacco control: the South African case of politics, health policy, health promotion and behaviour change. South African Med J. 2013;103(11):835. doi:10.7196/samj.6910

27. Tumwine J. Implementation of the framework convention on tobacco control in Africa: current status of legislation. Int J Environ Res Public Health. 2011;8(11):4312-4331. doi:10.3390/ijerph8114312

28. World Health Organization. Global progress report on implementation of the WHO framework convention on tobacco control 2018. 2018. Available from: https://www.who.int/fctc/reporting/WHOFCTC-2018_global_progress_report.pdf. Accessed June 26, 2021.

29. Abedian I, Jacobs R. Tobacco taxes and government revenue in South Africa. J Econ Stud. 2001;28(6):397-407. doi:10.1108/EUM0000 000006275

30. Blecher E. Taxes on tobacco, alcohol and sugar sweetened beverages: linkages and lessons learned. Soc Sci Med. 2015;136-137:175-179. doi:10.1016/j.socscimed.2015.05.022

31. Mapa-Tassou C, Bonono CR, Assah F, et al. Two decades of tobacco use prevention and control policies in Cameroon: results from the analysis of non-communicable disease prevention policies in Africa. BMC Public Health. 2018;18(S1):958. doi:10.1186/s12889-0185828-4

32. Robertson L, Nyamurungi KN, Gravely S, et al. Implementation of $100 \%$ smoke-free law in Uganda: a qualitative study exploring civil society's perspective. BMC Public Health. 2018;18(1):927. doi:10.1186/s12889-018-5869-8

33. Owusu-Dabo E, Lewis S, McNeill A, Gilmore A, Britton J. Support for smoke-free policy, and awareness of tobacco health effects and use of smoking cessation therapy in a developing country. BMC Public Health. 2011;11(1):572. doi:10.1186/1471-2458-11-572

34. Borland R. Theories of behavior change in relation to environmental tobacco smoke control to protect children. Available from: https:// www.who.int/tobacco/resources/publications/en/borland.pdf?ua=1. Accessed June 26, 2021.

35. Vellios N, Ross H, Perucic AM. Trends in cigarette demand and supply in Africa. PLoS One. 2018;13(8):1-13. doi:10.1371/journal. pone. 0202467

36. Otekunrin OA, Otekunrin OA, Momoh S, Ayinde IA. How far has Africa gone in achieving the zero hunger target? Evidence from Nigeria. Glob Food Sec. 2019;22:1-12. doi:10.1016/j. gfs.2019.08.001 
37. Otekunrin OA, Otekunrin OA, Sawicka B, Ayinde IA. Three decades of fighting against hunger in Africa: progress, challenges and opportunities. World Nutr. 2020;11(3):86-111. doi:10.26596/ wn.202011386-111

38. Mees HLP, Dijk J, van Soest D, Driessen PPJ, van Rijswick MH, Runhaar H. A method for the deliberate and deliberative selection of policy instrument mixes for climate change adaptation. Ecol Soc. 2014;19(2):art58. doi:10.5751/ES-06639-190258

39. Howlett M. Policy instruments, policy styles and policy implementation. Policy Stud J. 1991;19(2):1-21. doi:10.1111/ j.1541-0072.1991.tb01878.x

40. Bemelmans-Videc ML, Rist RC, Vedung E. Policy instruments: typologies choice and evaluation. 1998.

41. Jacob K, Peter King DM. Approach to assessment of policy effectiveness. In: Global Environment Outlook - GEO-6: Healthy Planet Healthy People. Cambridge University Press; 2019:272-281. doi:10.1017/9781108627146.016

42. MJ, McKenzie JE, Bossuyt PM, Boutron I, Hoffmann TC, Mulrow CD, et al. The PRISMA 2020 statement: an updated guideline for reporting systematic reviews. BMJ. 2021;372:n71. doi:10.1136/bmj.n71

43. Hood C. Intellectual obsolescence and intellectual makeovers: reflections on the tools of government after two decades. Governance. 2007;20(1):127-144. doi:10.1111/j.1468-0491.2007.00347.x

44. Lee R, den Uyl R, Runhaar H. Assessment of policy instruments for pesticide use reduction in Europe; Learning from a systematic literature review. Crop Prot. 2019;126:104929. doi:10.1016/j.cropro.2019.104929

45. Moher D, Liberati A, Tetzlaff J, Altman DG. Preferred reporting items for systematic reviews and meta-analyses: the PRISMA statement. PLoS Med. 2009;6(7):e1000097. doi:10.1371/journal.pmed.1000097

46. Munir MA, Kuganda H, Basry A. The efficacy and safety of antivirus drugs for COVID-19: a systematic review. Syst Rev Pharm. 2020;11:162-166.

47. Anthony M, Lin F. A systematic review for functional neuroimaging studies of cognitive reserve across the cognitive aging spectrum. Arch Clin Neuropsychol. 2018;33(8):937-948. doi:10.1093/arclin/acx125

48. McPheeters ML, Kripalani S, Peterson NB, et al. Closing the quality gap: revisiting the state of the science (vol. 3: quality improvement interventions to address health disparities). Evid Rep Technol Assess. 2012;208:1-475.

49. Herzog R, Álvarez-pasquin MJ, Díaz C, Del Barrio JL, Estrada JM, Gil Á. Are healthcare workers' intentions to vaccinate related to their knowledge, beliefs and attitudes? a systematic review. BMC Public Health. 2013;13(1):154. doi:10.1186/1471-2458-13-154

50. Atiba Y, Olubodun T, Odukoya O. Young Peoples' support for a smoke-free campus policy: a case for smoke-free campuses in the statewide smoking law in Lagos State, Nigeria. Ann Afr Med. 2020;19(1):53. doi:10.4103/aam.aam_27_19

51. Talley B, Masyn K, Chandora R, Vivolo-Kantor A. Multilevel analysis of school anti-smoking education and current cigarette use among South African students. Pan Afr Med J. 2017;26:1-12. doi:10.11604/pamj.2017.26.37.7880
52. Radwan GN, Emam AH, Maher KM, Mehrez M, El-Sayed N, ElNahas GM. Public opinion on smoke-free policies among Egyptians. Int J Tuberc Lung Dis. 2012;16(10):1412-1417. doi:10.5588/ ijtld.12.0079

53. Little M, Van Walbeek C. Restaurant smoking sections in South Africa and the perceived impact of the proposed smoke-free laws: evidence from a nationally representative survey. South African Med J. 2018;108(3):240. doi:10.7196/SAMJ.2018.v108i3.12683

54. Winkler V, Lan Y, Becher H. Tobacco prevention policies in west-African countries and their effects on smoking prevalence. BMC Public Health. 2015;15(1):1216. doi:10.1186/s12889-015-2562-z

55. Ayo-Yusuf OA, Olutola BG, Agaku IT. Permissiveness toward tobacco sponsorship undermines tobacco control support in Africa. Health Promot Int. 2016;31(2):414-422. doi:10.1093/heapro/dau102

56. Cheyip MYNCK, Nelson G, Ross MH, Murray J. South African platinum mine employees reduce smoking in 5 years. Tob Control. 2007;16(3):197-201. doi:10.1136/tc.2006.018861

57. Nargis N, Manneh Y, Krubally B, et al. How effective has tobacco tax increase been in the Gambia? A case study of tobacco control. BMJ Open. 2016;6(8):e010413. doi:10.1136/bmjopen-2015-010413

58. Tingum E, Mukong A, Mdege N. The effects of price and non-price policies on cigarette consumption in South Africa. Tob Induc Dis. 2020;18:62. doi:10.18332/tid/123424

59. Berthet Valdois J, Van Walbeek C, Ross H, et al. Tobacco industry tactics in response to cigarette excise tax increases in Mauritius. Tob Control. 2019:tobaccocontrol-2019-055196. doi:10.1136/tobaccocontrol-2019-055196

60. USGS-NASA. Planetary names: abbreviations for continents, countries, and ethnic groups. NASA; 2021. Available from: https://plane tarynames.wr.usgs.gov/Abbreviations. Accessed June 7, 2021.

61. Kaleta D, Polanska K, Usidame B. Smoke-free workplaces are associated with protection from second-hand smoke at homes in Nigeria: evidence for population-level decisions. Biomed Res Int. 2015;2015:1-8. doi:10.1155/2015/618640

62. Adeniji F. Consumption function and price elasticity of tobacco demand in Nigeria. Tob Prev Cessat. 2019;5. doi:10.18332/tpc/114084

63. Čizmović M, Laković T, Popović M, Mugoša A. The elasticity of tobacco products. 2018.

64. Otañez MG, Mamudu H, Glantz SA. Global leaf companies control the tobacco market in Malawi. Tob Control. 2007;16(4):261-269. doi:10.1136/tc.2006.019273

65. Mamudu H, Subedi P, Alamin A, et al. The progress of tobacco control research in Sub-Saharan Africa in the past 50 years: a systematic review of the design and methods of the studies. Int J Environ Res Public Health. 2018;15(12):2732. doi:10.3390/ijerph15122732

66. Shuriye AO, Ajala MT. The future of statehood in East Africa. J Sustain Dev. 2016;9(2):221. doi:10.5539/jsd.v9n2p221

67. Sawicka B, Otekunrin OA, Skiba D, Bienia B, Ćwintal M. Plantderived stimulants and psychoactive substances - social and economic aspects. Med Clin Res. 2020.
Risk Management and Healthcare Policy

\section{Publish your work in this journal}

Risk Management and Healthcare Policy is an international, peerreviewed, open access journal focusing on all aspects of public health, policy, and preventative measures to promote good health and improve morbidity and mortality in the population. The journal welcomes submitted papers covering original research, basic science, clinical \& epidemiological studies, reviews and evaluations, guidelines, expert opinion and commentary, case reports and extended reports. The manuscript management system is completely online and includes a very quick and fair peer-review system, which is all easy to use. Visit http://www.dovepress.com/testimonials.php to read real quotes from published authors. 